\title{
Use of the Arden grating test for screening
}

\author{
ROBERT G. WEATHERHEAD \\ From Moorfields Eye Hospital, City Road, London EC1V 2PD
}

SUMMARY One hundred and forty patients were referred for a clinical evaluation of their eyes, having produced high scores on screening by the Arden grating test (AGT). In these patients $66 \%$ of the eyes were found to be normal, $31 \%$ abnormal, and $3 \%$ indeterminate on clinical examination. Suitable criteria for referral for clinical examination were determined and the recommended scores are: $(a)$ A total AGT score of $\geqslant 80 ;(b)$ One or more plates scoring $\geqslant 17 ;(c)$ A difference between the two eyes of $\geqslant 13$. With these criteria at least $95 \%$ of the abnormal eyes will be detected. As a screening test the AGT is equal to the Snellen distance visual acuity test at separating the normal group from the abnormal group, and on the recommended criteria the AGT gives a better ratio of false positives to false negatives.

The Arden grating test is a subjective clinical test of visual function introduced in a portable book form by Arden and Jacobsen in 1976. ${ }^{12}$ The principle of the test is the measurement of contrast sensitivity by sine-wave gratings (Fig. 1). In this study a standard set of 6 plates in book form were used under controlled illumination conditions. The visual threshold for the gratings was measured for each of the 6 different spatial frequencies. Each eye was tested separately. The test yields a score, and there are many factors which affect this score. Among these are the age of the patient, ${ }^{3-6}$ number and form of the plates, ${ }^{34}$ illumination conditions, and the disease process from which the patient is suffering. ${ }^{13-578}$ The value of the AGT as a screening test for use by general practitioners and others is under consideration, and this aspect, as well as the identification of guidelines for clinical use, were the aims of this study.

\section{Materials and methods}

A total of 140 patients from the London area underwent a careful ophthalmic assessment at Moorfields Eye Hospital after a screening procedure done either in a general practitioner's rooms or in a general eye clinic. Seventeen general practitioners referred patients.

\section{SCREENING}

From an unrecorded number of patients visiting their general practitioners 138 patients were found to score above the screening criteria on the AGT. Of these, $73(52.9 \%)$ were screened because they presented with an eye complaint, $48(34.8 \%)$

Correspondence to Robert G. Weatherhead. because they were considered high risk-for example, had hypertension or angina-and $17(12.3 \%)$ were found on random screening.

The criteria for referral were arbitrarily taken at

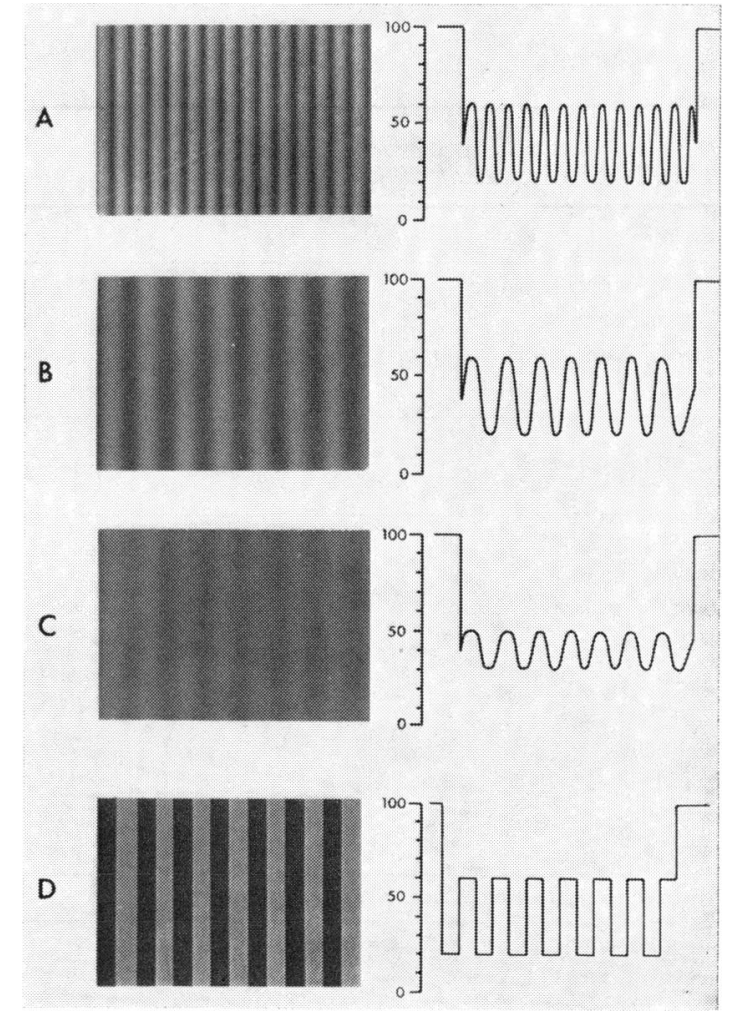

Fig. 1 Diagram showing the difference between sine-wave and square-wave gratings. 
(i) score over 78 in any one eye (it should be noted that the normal value previously claimed was 82 and that the value of 78 was set to include some false positives); (ii) asymmetry of scores in the 2 eyes greater than 10; (iii) a score on any plate over 16. An example of the scoring system used for the AGT is given in Table 1 , where 20 was the value given for any plate on which the gratings were not visible. In some studies this value is taken as 25 , so that their maximum score possible is 140 .

A further 2 patients from a general eye clinic were seen, thus giving a total of 140 patients.

\section{EXAMINATION}

At Moorfields Eye Hospital the patients had a repeat AGT done under standard conditions,

Table 1 Example of scoring system

\begin{tabular}{lll}
\hline Plate & Right eye & Left eye \\
\hline 2 & 11 & 12 \\
3 & 8 & 10 \\
4 & 12 & 18 \\
5 & 10 & 14 \\
6 & 12 & 17 \\
7 & 12 & Not seen \\
Total & 65 & 91 \\
\hline
\end{tabular}

Table 2 The results of clinical examination

\begin{tabular}{|c|c|c|c|c|c|}
\hline \multicolumn{6}{|l|}{ Results } \\
\hline \multicolumn{2}{|l|}{ Number of eyes tested } & \multicolumn{4}{|l|}{280} \\
\hline \multicolumn{2}{|l|}{ Abnormality found } & \multicolumn{4}{|c|}{$86(31 \%)$} \\
\hline \multicolumn{2}{|l|}{ Indeterminate } & \multicolumn{4}{|c|}{$10(3 \%)$} \\
\hline \multicolumn{2}{|l|}{ Normal } & \multicolumn{4}{|c|}{$184(66 \%)$} \\
\hline \multirow{2}{*}{\multicolumn{2}{|c|}{ Reason for abnormality }} & \multicolumn{4}{|c|}{ Snellen $V A$} \\
\hline & & \multicolumn{4}{|c|}{$6 / 5 \quad 6 / 6$} \\
\hline Cataract & 46 & 2 & 6 & 16 & 22 \\
\hline Macula & 10 & $\mathbf{0}$ & 2 & 3 & 5 \\
\hline Optic nerve disease & 7 & 1 & - & 2 & 4 \\
\hline Field defect & 7 & 2 & 3 & 2 & - \\
\hline Retinal & 5 & - & 2 & 2 & 1 \\
\hline Corneal & 3 & - & - & 3 & - \\
\hline Glaucoma & 3 & - & - & 1 & 2 \\
\hline Optical & 2 & - & - & 1 & 1 \\
\hline Amblyopia & 2 & - & - & - & 2 \\
\hline Embolic & 1 & - & 1 & - & - \\
\hline \multicolumn{6}{|c|}{ Reason for being indeterminate } \\
\hline \multicolumn{4}{|l|}{ Suspected amblyopia } & 3 & \\
\hline \multicolumn{4}{|c|}{ Previous ECT and leucotomy } & 2 & \\
\hline \multicolumn{4}{|c|}{ Colour blindness } & 2 & \\
\hline \multicolumn{4}{|c|}{ Personality problem with unreliable AGT scores } & 1 & \\
\hline
\end{tabular}

Table 3 The age distribution of the patients tested

\begin{tabular}{lcrrc}
\hline Age group & Total & \multicolumn{1}{c}{$N$} & \multicolumn{1}{c}{$A$} & $I$ \\
\hline $15-19$ & 2 & 1 & 1 & - \\
$20-24$ & 8 & 7 & - & 1 \\
$25-29$ & 10 & 9 & 1 & - \\
$30-34$ & 6 & 6 & - & - \\
$35-39$ & 14 & 12 & 2 & - \\
$40-44$ & 16 & 11 & 3 & 2 \\
$45-49$ & 10 & 10 & - & - \\
$50-54$ & 26 & 24 & 2 & - \\
$55-59$ & 26 & 19 & 6 & 1 \\
$60-64$ & 38 & 20 & 14 & 4 \\
$65-69$ & 62 & 38 & 23 & 1 \\
$70-74$ & 36 & 18 & 17 & 1 \\
$75-79$ & 14 & 7 & 7 & - \\
$80-84$ & 12 & 2 & 10 & - \\
Total & 280 & 184 & 86 & 10 \\
\hline
\end{tabular}

$\mathbf{N}=$ Normal. $\mathbf{A}=$ Abnormality found. $\mathbf{I}=$ Indeterminate.

followed by a thorough ophthalmological examination. Those patients requiring further investigative tests or treatment were referred to the various departments available at Moorfields Eye Hospitalfor example, the electrodiagnostic department, the retinodiagnostic department.

\section{FOLLOW-UP}

On the basis of this clinical examination the patient was considered normal, abnormal, or indeterminate. Those patients who had a normal examination but a high AGT score were recalled 2 to 12 months later (average 6 months), and a repeat AGT and visual assessment was done.

There were 71 patients in this group. Fifty-two patients reattended and were found to have different AGT scores, though clinically they were unchanged. Nineteen patients failed 3 times to reattend for follow-up.

\section{Results}

Seventy-one patients who were clinically normal but who had high AGT scores were recalled (Table 2). Nineteen failed to reattend, 1 had died, and 1 had had a stroke. Fifty-two reattended (104 eyes). Eighty-one were better (by 1-21, average 10), 17 were worse (by 1-28, average 8), and 6 had the same score.

Table 3 shows the age distribution of the patients tested and the distribution of the normal and abnormal groups (most are in the elderly age group).

Table 4 shows the distribution of the AGT scores and the breakdown of the group into normal and abnormal groups. Considering each of the groups 
from this population the following emerges. (a) Normal eyes $(n=184)$ : mean 76.8 , median 75 , standard deviation 8.7. (b) Abnormal eyes $(n=86)$ : mean $95 \cdot 5$, median 95 , standard deviation $8 \cdot 3$. (c) Indeterminate eyes $(n=10)$.

The distribution of Snellen distance visual acuity scores is given in Table 5 .

Fig. 2 and Table 6 show that there is a highly significant difference in the separation of the normal and abnormal groups by the Arden grating and Snellen distance visual acuity tests.

A cumulative frequency graph and a table were constructed from the data to show the false positive and false negative rates for the AGT and the Snellen test (Fig. 3 and Table 7). A false positive

Table 4 The distribution of the AGT scores

\begin{tabular}{lcrcc}
\hline AGT score & Total & $N$ & $A$ & $I$ \\
\hline $56-60$ & 2 & 2 & - & - \\
$61-65$ & 9 & 9 & - & - \\
$66-70$ & 30 & 28 & 1 & 1 \\
$71-75$ & 60 & 57 & 3 & - \\
$76-80$ & 54 & 46 & 6 & 2 \\
$81-85$ & 26 & 13 & 10 & 3 \\
$86-90$ & 28 & 15 & 11 & 2 \\
$91-95$ & 19 & 5 & 13 & 1 \\
$96-100$ & 15 & 6 & 8 & 1 \\
$101-105$ & 17 & 1 & 16 & - \\
$106-110$ & 11 & 2 & 9 & - \\
$111-115$ & 5 & - & 5 & - \\
$116-120$ & 4 & - & 4 & - \\
Total & 280 & 184 & 86 & 10 \\
\hline
\end{tabular}

$\mathbf{N}=$ Normal. $\mathbf{A}=$ Abnormality found. $\mathbf{I}=$ Indeterminate.
Table 5 The distribution of the Snellen distance VA scores

\begin{tabular}{lrr}
\hline $\begin{array}{l}\text { Snellen distance } \\
\text { visual acuity }\end{array}$ & $N$ & $A$ \\
\hline $6 / 5$ & 81 & 5 \\
$6 / 6$ & 65 & 14 \\
$6 / 9$ & 33 & 30 \\
$6 / 12$ & 5 & 13 \\
$6 / 18$ & - & 14 \\
$6 / 24$ & - & 4 \\
$6 / 36$ & - & 2 \\
$6 / 60$ & - & 1 \\
$<6 / 60$ & - & 3 \\
Total & 184 & 86 \\
\hline
\end{tabular}

$\mathrm{N}=$ Normal. A = Abnormality found.

Table 6 Comparison of the AGT and Snellen scores

\begin{tabular}{|c|c|c|c|c|}
\hline & \multicolumn{2}{|l|}{$A G T$} & \multicolumn{2}{|l|}{ Snellen } \\
\hline & Normals & Abnormals & Normals & Abnormals \\
\hline Number & 184 & 86 & 184 & 86 \\
\hline Mean & $76 \cdot 8$ & $95 \cdot 5$ & $30 \cdot 44^{*}$ & $18 \cdot 38 *$ \\
\hline Standard deviation & 8.7 & $8 \cdot 3$ & $6 \cdot 30$ & 8.79 \\
\hline $\begin{array}{l}\text { Standard error of } \\
\text { the mean }\end{array}$ & 0.64 & 0.89 & 0.46 & 0.95 \\
\hline $\begin{array}{l}\text { Difference between } \\
\text { means }\end{array}$ & & $18 \cdot 7$ & & $12 \cdot 06$ \\
\hline \multicolumn{5}{|c|}{$\begin{array}{l}\text { Difference between means } \\
\text { Combined standard error of the means }\end{array}$} \\
\hline$=t$ value & & $16 \cdot 69$ & & $12 \cdot 85$ \\
\hline Associated $P$ valu & & 0.001 & & $<0.001$ \\
\hline
\end{tabular}

-In cycles/degree assuming 6/6 $=30$ cycles/degree.

This analysis means that there is a highly significant difference in the separation of the normal and abnormal groups by the 2 tests.
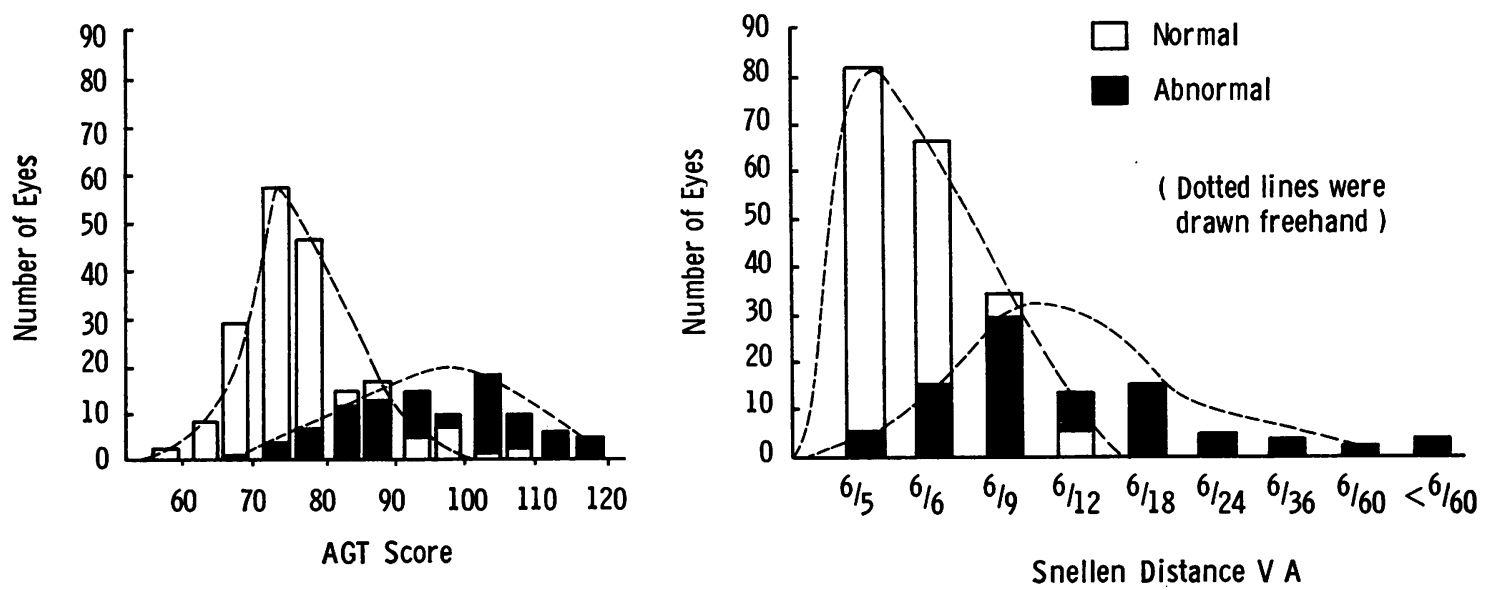

Fig. 2 A comparison of histograms constructed from the AGT scores and Snellen test scores achieved by the same patients. 

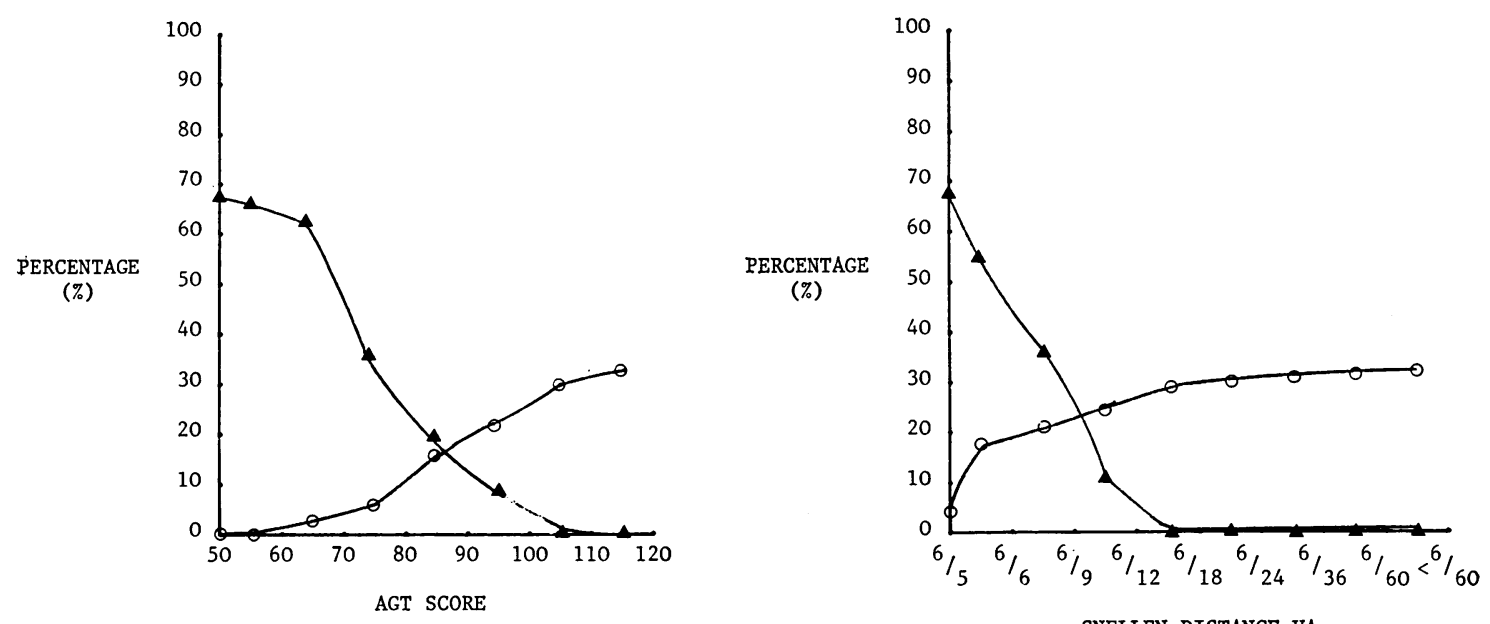

SNELLEN DISTANCE VA

Fig. 3 Cumulative frequency graph showing the curves for the false positive and false negative rates. $\Delta=$ False positive rate. $\Delta=$ False negative rate. Connecting lines were drawn freehand.

Table 7 False positiv and false negative rates for the $A G T$ and the Snellen test

\begin{tabular}{cccc}
\hline & & False positive & False negative \\
\hline AGT & below 50 & $184 / 270=68 \cdot 1 \%$ & $0 \%$ \\
& $\leqslant 60$ & $182 / 268=67 \cdot 9 \%$ & $0 / 11=0 \%$ \\
$\leqslant 70$ & $145 / 230=63 \cdot 0 \%$ & $1 / 40=2 \cdot 5 \%$ \\
& $\leqslant 80$ & $42 / 118=35 \cdot 6 \%$ & $10 / 152=6 \cdot 6 \%$ \\
& $\leqslant 90$ & $14 / 69=20 \cdot 3 \%$ & $31 / 201=15 \cdot 4 \%$ \\
& $\leqslant 100$ & $3 / 37=8 \cdot 1 \%$ & $52 / 233=22 \cdot 3 \%$ \\
& $\leqslant 110$ & $0 \%$ & $77 / 261=29 \cdot 5 \%$ \\
Snellen test & $\leqslant 120$ & $0 \%$ & $86 / 270=31 \cdot 8 \%$ \\
$6 / 5$ & $184 / 270=68 \cdot 1 \%$ & $5 / 86=5 \cdot 8 \%$ \\
$6 / 6$ & $103 / 184=55 \cdot 9 \%$ & $19 / 105=18 \cdot 1 \%$ \\
$6 / 9$ & $38 / 105=36 \cdot 2 \%$ & $49 / 228=21 \cdot 5 \%$ \\
$6 / 12$ & $5 / 42=11 \cdot 9 \%$ & $62 / 246=25 \cdot 2 \%$ \\
$6 / 18$ & $0 \%$ & $76 / 260=29 \cdot 2 \%$ \\
$6 / 24$ & $0 \%$ & $80 / 264=30 \cdot 3 \%$ \\
$6 / 36$ & $0 \%$ & $82 / 266=30 \cdot 8 \%$ \\
$6 / 60$ & $0 \%$ & $83 / 267=31 \cdot 1 \%$ \\
$<6 / 60$ & $0 \%$ & $86 / 270=31 \cdot 8 \%$ \\
\hline
\end{tabular}

is a person who is clinically normal yet scores above the criteria on the test, and a false negative is one who is clinically abnormal and scores below the criteria on the test.

Fig. 4 and Table 8 show the effect of using 1 or more plates scoring 17 or more. It can be seen that the 2 curves separate further with the increase in number of high scoring plates.

Using the difference in scores between the two eyes we see among the 20 patients who had one eye normal and the fellow eye abnormal clinically the range of scores was -8 to +32 , mean $+15 \cdot 1$; while among the 80 patients with both eyes normal on clinical examination the range of scores was 0 to

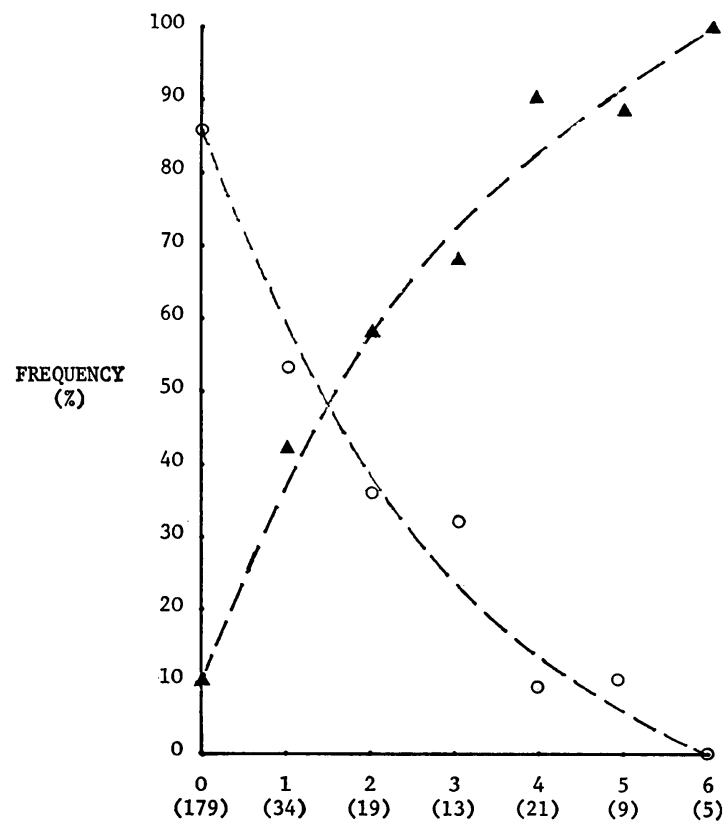

NUMBER OF PLATES SCORING 17 OR MORE

Fig. 4 Graph showing the differentiating effect of using the individual plate scores. There are insufficient numbers in some groups, but the trend can be seen. $\Delta=$ Abnormal eyes. $O=$ Patients with normal eyes. Connecting lines were drawn freehand. 
+16 , mean $+3 \cdot 3$. These two groups are compared in Fig. 5 and Table 9.

There are 'grey areas' where the AGT score cannot necessarily be correlated with a detected abnormality for example, in migraine with a transient field defect but no residual damage. In this study 1 patient with a very high AGT score had 6/5 vision in both eyes and normal Goldmann and Friedmann fields. Another example is the presence of fine macular drusen, again with $6 / 5$ vision. The AGT may be detecting an abnormality before that abnormality is affecting other visual function parameters. There were other disease processes which may have affected the AGT score but which could not be

Table 8 The effect of using supplementary screening criteria: using the number of plates scoring 17 or more

\begin{tabular}{lrrrr}
\hline $\begin{array}{l}\text { Number of plates } \\
\text { scoring } 17 \text { or } \\
\text { more }\end{array}$ & $\begin{array}{l}\text { Total number } \\
\text { in group }\end{array}$ & $N$ & \multicolumn{1}{c}{$A$} & $I$ \\
\hline 0 & 179 & 152 & 20 & 7 \\
1 & 34 & 18 & 14 & 2 \\
2 & 19 & 7 & 11 & 1 \\
3 & 13 & 4 & 9 & - \\
4 & 21 & 2 & 19 & - \\
5 & 9 & 1 & 8 & - \\
6 & 5 & - & 5 & - \\
Total & 280 & 184 & 86 & 10 \\
\hline
\end{tabular}

$\mathbf{N}=$ Normal. $\mathbf{A}=$ Abnormality found. $\mathbf{I}=$ Indeterminate.

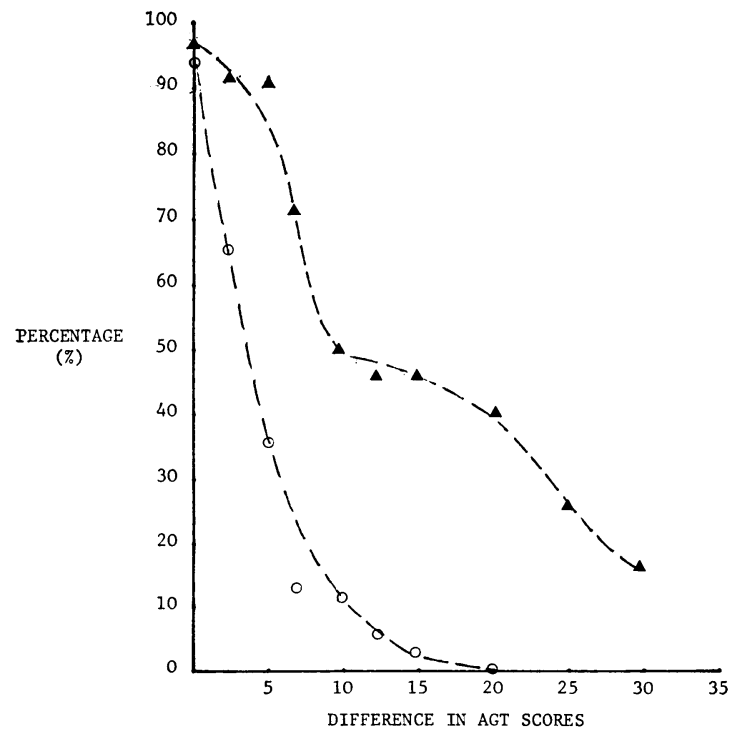

Fig. 5 Cumulative frequency graph plotting the differences between the 2 eyes. $\mathbf{A}=$ Patients with one eye normal and fellow eye abnormal. $\bigcirc=$ Patients with both eyes normal. Connecting lines were drawn freehand.
Table 9 The effect of using supplementary screening criteria: using the difference between the 2 eyes

\begin{tabular}{ccc}
\hline Difference & Both eyes normal & $\begin{array}{l}\text { One eye normal } \\
\text { other eye abnormal }\end{array}$ \\
\hline $0-2 \cdot 5$ & $75 / 80 \quad 93 \cdot 75 \%$ & $19 / 20=95 \%$ \\
$2 \cdot 5-4 \cdot 9$ & $52 / 80=65 \%$ & $18 / 20=90 \%$ \\
$5-7 \cdot 5$ & $29 / 80=36 \cdot 25 \%$ & $18 / 20=90 \%$ \\
$7 \cdot 5-9 \cdot 9$ & $13 / 80=16 \cdot 25 \%$ & $14 / 20=70 \%$ \\
$10-12 \cdot 5$ & $9 / 80=11 \cdot 25 \%$ & $10 / 20=50 \%$ \\
$12 \cdot 5-14 \cdot 9$ & $4 / 80=5 \%$ & $9 / 20=45 \%$ \\
$15-19 \cdot 9$ & $2 / 80=2 \cdot 5 \%$ & $9 / 20=45 \%$ \\
$20-24 \cdot 9$ & $0 \%$ & $8 / 20=40 \%$ \\
$25-29 \cdot 9$ & $0 \%$ & $5 / 20=25 \%$ \\
$30+$ & $0 \%$ & $3 / 20=15 \%$ \\
\hline
\end{tabular}

confirmed-for example, a diagnosis of suspected vertebrobasilar insufficiency. This is essentially a clinical diagnosis, and proving this would entail angiography with all its inherent risks.

\section{Discussion}

When using the total AGT score, to determine the best value to use it is necessary to consider: (i) a clinically acceptable level of false negatives; (ii) the importance of those false negatives; (iii) the retio of false positives to false negatives.

(i) Few guidelines are available in setting an acceptable false negative rate for visual screening, but if the level were set at $5 \%$ then the corresponding value for the AGT is 79 . The equivalent on the Snellen test is $6 / 5$.

(ii) Table 10 was drawn up to examine those abnormalities missed, to see whether this is critical or not. Three of the patients had conditions which require early investigation, namely, optic atrophy, optic nerve head infarct, and central retinal vein occlusion, and in this regard the value of 79 is too high. However, a lower value would mean the need to examine more people.

(iii) At 79 the ratio of false positives to false negatives is approximately $8: 1$ for the AGT, and the corresponding ratio for the Snellen is approximately 13:1.

When using the supplementary criteria to aid the detection of abnormal eyes:

(i) Number of plates scoring $\geqslant 17$. The results reflect the overall trend in the total AGT score, that is, the greater the number of high-scoring plates the greater the AGT value and the more likelihood there is of an abnormality. However, 3 out of the 9 false negatives on the AGT score alone would have been detected by this added criterion (Table 10).

(ii) Difference between the 2 eyes. $95 \%$ of the 
Table 10 Analysis of those abnormals who scored less than 79 on the $A G T$

\begin{tabular}{|c|c|c|c|c|}
\hline$A G T$ score & Disease & $\begin{array}{l}\text { Difference } \\
\text { between } \\
\text { the } 2 \text { eyes }\end{array}$ & $\begin{array}{l}\text { Number of } \\
\text { plates } \geqslant 17\end{array}$ & Snellen \\
\hline 79 & Cataract + & 4 & 1 & $6 / 18$ \\
\hline 79 & Cataract + & 2 & 1 & $6 / 9$ \\
\hline 79 & $\begin{array}{l}\text { Optic } \\
\text { atrophy + }\end{array}$ & 19 & $\mathbf{0}$ & $6 / 5$ \\
\hline 78 & $\begin{array}{l}\text { Probable old } \\
\text { infarct of optic } \\
\text { nerve head }\end{array}$ & 10 & 0 & $6 / 9$ \\
\hline 76 & Cataract + & 5 & 0 & $6 / 5$ \\
\hline 75 & Cataract + & 6 & 1 & $6 / 18$ \\
\hline 75 & $\begin{array}{l}\text { Compensated } \\
\text { CRVO }\end{array}$ & 2 & $\mathbf{0}$ & $6 / 6$ \\
\hline 73 & $\begin{array}{r}\text { Anterior corneal } \\
\text { dystrophy }++\end{array}$ & $\begin{array}{r}4 \\
+\quad 4\end{array}$ & 0 & $6 / 9$ \\
\hline 69 & $\begin{array}{c}\text { Anterior corneal } \\
\text { dystrophy }++\end{array}$ & $\begin{array}{r}4 \\
+\quad 4\end{array}$ & 0 & $6 / 9$ \\
\hline
\end{tabular}

CRVO = Central retinal vein occlusion.

normal group have a difference of $<13$ between their two eyes. A further one false negative was detected by this extra criterion. It is interesting to note that a further three false negatives had a Snellen visual acuity of worse than $6 / 6$.

In summary then, the criteria which are recommended for use in screening are: (1) Total score of $\geqslant 80$; (2) one or more plates scoring $\geqslant 17$; (3) a difference between the 2 eyes of $\geqslant 13$.

PLACE OF THE AGT IN A CLINICAL SETTING The AGT is of value as a screening test because the ratio of false positives to false negatives is better than with the Snellen, though both tests are good at separating normals from abnormals.

It should be noted here that in order to make the comparison of AGT and Snellen tests as stringent as possible the patients were considerably encouraged to achieve their best Snellen and AGT acuities, and this involved refraction in many cases (though the AGT result does not greatly depend on refraction. Since most screeners will have neither the time nor the facilities to do this, there is likely to be a difference between their results and those recorded here. With the score obtained by the general practitioner the average difference was 10.3 AGT units in this study $(27 \%$ of the general practitioner scores were lower, $69 \%$ higher, and $4 \%$ the same). This means that in testing by a general practitioner the AGT would yield more false positives, and this would tend to counteract any slight difference between the AGT and the Snellen test for screening purposes. Hence there is little to be gained from its use here. However, it would seem logical to use the AGT as a supplementary test in general and special eye clinics, such as retinal, macular, glaucoma, and neuro-ophthalmology clinics.

I should like to thank Mrs Sandra Max, Mrs Elizabeth Cosgrove, Dr Conrad Harris, Professor G. Arden, the secretaries, and the staff of Moorfields Eye Hospital for their help in this project.

This project was funded by a Medical Research Council Grant.

\section{References}

1 Arden GB, Jacobson JJ. A simple grating test for contrast sensitivity: preliminary results indicate value in screening for glaucoma. Invest Ophthalmol Visual Sci 1978; 17: 23-32.

2 Minassian DC, Jones BR, Zargarizadeh A. The Arden grating test of visual function: a preliminary study of its practicability and application in a rural community in north-west Iran. Br J Ophthalmol 1978; 62: 210-12.

3 Arden GB. The importance of measuring contrast sensitivity in cases of visual disturbance. Br J Ophthalmol 1978; 62: 198-209.

4 Arden GB. Visual loss in patients with normal visual acuity. Trans Ophthalmol Soc UK 1978; 98: 219-31.

5 Arundale $K$. An investigation into the variation of human contrast sensitivity with age and ocular pathology. $\mathrm{Br} J$ Ophthalmol 1978; 62: 213-5.

6 Weale RA. Senile changes in visual acuity. Trans Ophthalmol Soc UK 1975; 95: 36-8.

7 Sjøstrand J, Frizen L. Contrast sensitivity in macular disease. Acta Ophthalmol (Kbh) 1977; 55: 507-14. 